\title{
HUBUNGAN RELIGIUSITAS DENGAN TINDAKAN SKRINING KANKER PAYUDARA PADA WANITA DI WILAYAH KERJA PUSKESMAS PANDAK I BANTUL YOGYAKARTA
}

\author{
Dwi Kartika Rukmi ${ }^{\star *}$, Yanita Trisetiyaningsih ${ }^{2}$, Andria Fistra Aryu Brata D. ${ }^{3}$ \\ ${ }^{1 *, 2}$ Stikes Jenderal Achmad Yani Yogyakarta. Jl Brawijaya Ring Road Barat Ambarketawang, Gamping, \\ Sleman, Yogyakarta, email: kartikarukmi@gmail.com; ners_yanita@yahoo.co.id \\ ${ }^{3}$ Puskesmas Pandak I, Bantul, Yogyakarta, email: andriafistra@yahoo.co.id
}

\begin{abstract}
Background: Cancer is one of the leading causes of death worldwide. Breast cancer screening involves breast self-examination (BSE), clinical breast examination (SADANIS), and mammography. The high rates of breast cancer result from the low number of women who screen for breast. As an important thing, religiosity affecting healthy behaviors and illnesses including the cancer screening action are rarely studied.

Objective: The objective of this research is to identify the correlation between religiosity with women's breast cancer screening in the working area of Pandak I Community Health Center, Bantul District, Yogyakarta.

Method: This is a correlational analytical research along with a cross sectional approach. This research involved 397 respondents aged 20 years old or older than the age in question and they were not suffering from breast cancer measured by using an accidental sampling technique. The data collection technique was a questionnaire and the data processing dealt with the Spearman Rho.

Results: The majority of respondents' religiosity was moderate $(77.3 \%)$ and the majority of breast cancer screening measurements was low (59.4\%). The Spearman Rho test results showed no relation between religiosity with women's breast cancer screening action in the working area of Pandak I Community Health Center, Bantul District, Yogyakarta (Pv: 0,938, Sig: 0,05). The Spearman correlation value was 0.004, indicating that the correlation direction was positive along with the weakest correlation strength.

Conclusion: Breast cancer screening measurements are low and unrelated to the level of religiosity. The reason for not doing breast cancer screening action largely depends on the belief that health is determined by God. Therefore, nurses should further enhance the promotion of health education regarding breast cancer screening measurements using an approach other than religiosity.
\end{abstract}

Keywords: Breast cancer, religiosity, screening, women

\section{PENDAHULUAN}

Penyakit kanker merupakan salah satu penyebab kematian utama di seluruh dunia. Kanker payudara merupakan penyakit kanker dengan persentase kasus baru tertinggi. ${ }^{1}$ Prognosis dari kanker payudara erat kaitannya dengan pada stadium berapa kanker tersebut ditegakkan. Diagnosis yang lebih awal akan membantu mengurangi mortalitas akibat kanker payudara, oleh karena itu beberapa program skrining dan diagnostik awal dikembangkan untuk mendeteksi kanker payudara di stadium awal. Beberapa penelitian menunjukkan bahwa mortalitas penderita kanker payudara yang mengikuti program skrining menurun sampai dengan $40 \%{ }^{2}$

Skrining kanker payudara adalah kegiatan mendeteksi kanker sedini mungkin untuk menurunkan angka kematian akibat kanker payudara. $^{3}$ Di Indonesia, self examination atau pemeriksaan payudara sendiri (SADARI), clinical breast examination (CBE) atau pemeriksaan payudara klinis (SADANIS), dan mammografi dijadikan acuan untuk skrining kanker payudara. ${ }^{1}$

Walaupun metode skrining kanker payudara sudah lama disosialisasikan, 
namun pada kenyataannya angka kejadian kanker payudara di Indonesia masih tetap tinggi. ${ }^{1}$ Tingginya angka kanker payudara diduga karena masih rendahnya tindakan skrining kanker payudara yang akhirnya memengaruhi juga keterlambatan pasien dalam mencari pertolongan kesehatan karena kondisi yang dialami juga terlambat didiagnosis. $^{4} \quad$ Beberapa penelitian menemukan bahwa ketidakpatuhan terhadap panduan skrining kanker payudara (BSE, $C B E$, dan mammografi), takut, denial, memilih terapi alternatif, prioritas, low perceived risk, percaya bahwa gejala akan sembuh sendiri, cancer fatalism beliefs, spiritualitas dan religiusitas turut berkontribusi terhadap lambatnya seseorang dalam mencari pertolongan untuk kanker payudara yang dialaminya. ${ }^{5}$

Religiusitas dan spiritualitas adalah dua hal penting yang dapat memengaruhi keputusan seseorang mengenai hal hal yang berhubungan dengan kesehatannya. ${ }^{5}$ Banyak penelitian yang menjelaskan bahwa semakin tinggi level religiusitas seseorang maka secara umum akan semakin baik pula health -related quality of life orang tersebut. $^{6}$ Beberapa penelitian menyebutkan bahwa pasien dengan penyakit yang berat dan kronis akan semakin meningkat religiusitasnya. ${ }^{6}$ Sebagai contoh, pasien HIV dilaporkan mengalami peningkatan religiusitas sebesar $45 \%$ setelah didiagnosa. ${ }^{7}$

Namun ada juga peneliti yang berpendapat bahwa pengaruh religiusitas tidak selalu positif terhadap kesehatan. Dessio et al (2004) menemukan bahwa religiusitas dan spiritualitas berhubungan dengan keterlambatan pencarian pelayanan kesehatan pada wanita African American. ${ }^{4}$ Religiusitas dan spiritualitas sering dilihat sebagai penghalang bagi para wanita tersebut untuk mencari pelayanan kesehatan terkait kondisi sakit serius seperti kanker. ${ }^{4}$

Saat ini prevalensi kanker tertinggi nasional ada di Yogyakarta, yaitu sebesar $4,1 \%$, jauh lebih tinggi dibandingkan dengan angka nasional. ${ }^{1}$ Masih tingginya angka kanker payudara di Yogyakarta dapat disebabkan karena masih rendahnya angka wanita yang melakukan skrining payudara. Berdasarkan studi lintas etnik, halangan umum untuk seorang wanita melakukan skrining payudara antara lain adalah tidak memiliki cukup waktu dan akses pelayanan kesehatan (uang, asuransi, dan transportasi). ${ }^{3}$ Sedangkan religiusitas sebagai salah satu hal yang dianggap memengaruhi perilaku sehat dan sakit seseorang termasuk di dalamnya tindakan skrining kanker masih sedikit diteliti. Tujuan penelitain ini mengetahui hubungan antara religiusitas dengan tindakan skrining kanker payudara pada wanita di Wilayah Kerja Puskesmas Pandak I, Bantul, Yogyakarta

\section{BAHAN DAN CARA PENELITIAN}

Penelitian analitik korelasional dengan pendekatan cross sectional yang dilakukan di Desa Wijirejo dan Gilangharjo, 
Wilayah Kerja Puskesmas Pandak I, Bantul, Yogyakarta.

Sampel adalah 397 wanita yang memenuhi inklusi yaitu berusia $\geq 20$ tahun dan tidak sedang menderita kanker payudara, menggunakan teknik accidental sampling selama 4 bulan.

Pengumpulan data dilakukan dengan 3 kuesioner yaitu: 1) kuesioner karakteristik demografi dan faktor risiko responden 2) kuesioner skrining kanker payudara dan 3) kuesioner religiusitas dengan pengisian mandiri atau dibacakan untuk yang tidak bisa membaca.

Analisis data univariat dengan deskriptif prosentase dan analisis bivariat dengan Spearman Rho karena data tidak terdistribusi normal.

\section{HASIL DAN PEMBAHASAN}

Hasil penelitian berupa karakteristik responden berdasarkan demografi adalah sebagai berikut:

Berdasarkan tabel 1 didapatkan bahwa mayoritas responden berusia 20-50 tahun (81.1\%), berpendidikan SMA (47.6\%), bekerja pada sektor swasta $(48 \%)$, menikah (89.7\%) dan beragama Islam (73.3\%).

Berdasarkan tabel 2 di bawah mayoritas responden berada pada resiko rata rata kecuali untuk riwayat menarche dini/di bawah 12 tahun (71\%) dan mengikuti KB hormonal (56.9\%) yang termasuk dalam kategori resiko tinggi.
Berdasarkan tabel 3 didapatkan bahwa religiusitas responden mayoritas dalam kategori sedang $(77,3 \%)$ dan tindakan skrining kanker payudara berada pada kategori kurang $(59,4 \%)$.

Tabel 1. Karakteristik Demografi

\begin{tabular}{lcc}
\hline \multicolumn{1}{c}{ Demografi } & $\Sigma$ & $\%$ \\
\hline Usia & & \\
20-50 tahun & 322 & 81.1 \\
$>50$ tahun & 75 & 18.9 \\
& & \\
\hline Pendidikan & & \\
SD & 32 & 8.1 \\
SMP & 99 & 24.9 \\
SMA & 189 & 47.6 \\
PT & 77 & 19.4 \\
& & \\
\hline $\begin{array}{l}\text { Pekerjaan } \\
\text { PNS }\end{array}$ & 67 & 16.9 \\
Swasta & 192 & 48.4 \\
Tidak Bekerja & 138 & 34.8 \\
& & \\
\hline Status Pernikahan & & \\
Menikah & 356 & 89.7 \\
Belum Menikah & 23 & 5.8 \\
Janda & 18 & 4.5 \\
& & \\
\hline Agama & & \\
Islam & & \\
Kristen & 291 & 73.3 \\
Katolik & 55 & 13.9 \\
Hindu & 47 & 11.8 \\
$\quad$ Total & 4 & 1 \\
\hline & 397 & 100 \\
\hline
\end{tabular}

Sumber: Data Primer, 2017

Tabel 2. Faktor Risiko Responden

\begin{tabular}{|c|c|c|}
\hline Faktor Risiko & $\sum$ & $\%$ \\
\hline \multicolumn{3}{|c|}{ Riwayat Ca PD Keluarga } \\
\hline Ya & 9 & 2.3 \\
\hline Tidak & 388 & 97.7 \\
\hline \multicolumn{3}{|c|}{ Riw Tumor/Kanker Payudara Pasien } \\
\hline $\mathrm{Ya}$ & 6 & 1.5 \\
\hline Tidak & 391 & 98.5 \\
\hline \multicolumn{3}{|l|}{ Usia menarche } \\
\hline$\leq 12$ tahun & 282 & 71 \\
\hline$>12$ tahun & 115 & 29 \\
\hline
\end{tabular}




\begin{tabular}{lcc}
\hline Riwayat Menopause & & \\
Belum Menopause & 340 & 85 \\
$\leq 55$ tahun & 42 & 10.6 \\
$>55$ tahun & 15 & 3.8 \\
\hline Memiliki Anak & & \\
Ya & 350 & 88.2 \\
Tidak & 47 & 11.8 \\
\hline KB Hormonal & & \\
Ya & 226 & 56.9 \\
Tidak & 171 & 43.1 \\
\hline Obesitas & & \\
Ya & 111 & 28 \\
Tidak & 286 & 72 \\
\hline Konsumsi Alkohol & & \\
Ya & 2 & 5 \\
Tidak & 395 & 99.5 \\
\hline Riwayat Rontgen Dada & & \\
Ya & 25 & 6.3 \\
Tidak Total & 372 & 93.7 \\
\hline \multicolumn{2}{c}{397} & 100 \\
\hline Sumber: Data Primer, 2017 & &
\end{tabular}

Tabel 3. Religiusitas dan Skrining $\mathrm{Ca}$ Payudara Responden

\begin{tabular}{clcc}
\hline Variabel & Kategori & $\sum$ & $\%$ \\
\hline Religiusitas & Rendah & 29 & 7.3 \\
& Sedang & 307 & 77.3 \\
& Tinggi & 61 & 15.4 \\
\hline Skrining & Kurang & 236 & 59.4 \\
& Sedang & 107 & 27 \\
& Baik & 54 & 13.6 \\
\hline & Total & 397 & 100 \\
\hline
\end{tabular}

Sumber: Data Primer, 2017

Tabel 4. Alasan Tidak Melakukan Skrining Ca Payudara pada Responden

\begin{tabular}{lcc}
\hline \multicolumn{1}{c}{ Alasan } & $\sum$ & $\%$ \\
\hline $\begin{array}{l}\text { Merasa tidak ada masalah } \\
\text { dengan payudara }\end{array}$ & 123 & 31 \\
$\begin{array}{l}\text { Tidak tahu bagaimana cara } \\
\text { melakukan skrining payudara }\end{array}$ & 35 & 8.8 \\
$\begin{array}{l}\text { Tidak memiliki cukup dana untuk } \\
\text { melakukan pemeriksaan }\end{array}$ & 2 & 0.5 \\
$\begin{array}{l}\text { Takut } \\
\begin{array}{l}\text { Sibuk dengan pekerjaan/ } \\
\text { rutinitas sehari hari }\end{array}\end{array}$ & 51 & 12.8 \\
$\begin{array}{l}\text { Percaya bahwa kesehatan } \\
\text { sudah ditentukan oleh Tuhan }\end{array}$ & 145 & 36.5 \\
\hline \multicolumn{1}{c}{ Total } & 397 & 100 \\
\hline
\end{tabular}

Sumber: Data Primer, 2017

Alasan responden tidak melakukan skrining kanker payudara berdasarkan tabel
4 adalah percaya bahwa kesehatan sudah ditentukan oleh Tuhan (36,5\%).

Tabel 5. Hasil Uji Statistik Bivariat

\begin{tabular}{cccrr}
\hline & & & Rlg & Skr \\
\hline $\begin{array}{c}\text { Spear } \\
\text { man } \\
\text { Rho }\end{array}$ & Religi & $\begin{array}{c}\text { Corr } \\
\text { usitas }\end{array}$ & 1.000 & .004 \\
& & coeffisient & & \\
\cline { 2 - 5 } & & Sig.(2 tailed) &. & .938 \\
\cline { 2 - 5 } & $\begin{array}{c}\text { Skrini } \\
\text { ng }\end{array}$ & $\begin{array}{c}\text { Corr } \\
\text { coeffisient }\end{array}$ & 397 & 397 \\
\cline { 2 - 4 } & & Sig.(2 tailed) & .904 & 1.000 \\
\cline { 2 - 4 } & & $\mathrm{N}$ & 397 & 397 \\
\hline
\end{tabular}

Sumber: Data Primer, 2017

Hasil uji Spearman Rho (tabel 5) didapatkan tidak ada hubungan antara religiusitas dengan skrining kanker payudara pada wanita di wilayah kerja Puskesmas Pandak I, Kabupaten Bantul, Yogyakarta (Pv:0,938,Sig:0,05). Nilai korelasi Spearman didapatkan sebesar 0.004 yang menunjukkan bahwa arah korelasi positif dengan kekuatan korelasi yang sangat lemah.

Menurut Komite Nasional Penanggulangan Kanker, ${ }^{1}$ faktor risiko yang erat kaitannya dengan peningkatan insiden kanker payudara antara lain adalah jenis kelamin wanita, usia > 50 tahun, riwayat keluarga dan genetik (pembawa mutasi gen BRCA1, BRCA2, ATM atau TP53 (p53)), riwayat penyakit payudara sebelumnya (DCIS pada payudara yang sama, LCIS, densitas tinggi pada mamografi), riwayat menarche dini (<12 tahun) atau menopause lambat (>55 tahun), riwayat reproduksi (tidak memiliki anak dan tidak menyusui), hormonal, obesitas, konsumsi alkohol,riwayat radiasi dinding dada, dan faktor lingkungan. Mayoritas responden berada dalam kategori 
risiko rata-rata kecuali untuk riwayat menarchei dini (di bawah 12 tahun), dan mengikuti KB hormonal.

Sebagian besar penelitian studi kasus menyatakan bahwa menarche dini $\quad<12$ tahun) akan meningkatkan risiko terkena kanker payudara terutama bila disertai juga dengan menopause terlambat (> 55 tahun). Riwayat menarche dini merupakan factor risiko kanker payudara dikarenakan wanita yang mengalami menarche dini $(<12$ tahun) akan mengalami siklus menstruasi yang lebih banyak sehingga akan lebih lama terpapar dengan hormon estrogen dan progesteron yang berpengaruh terhadap proses proliferasi jaringan termasuk jaringan payudara. ${ }^{8,9}$ Pertumbuhan jaringan payudara sangat sensitif terhadap estrogen sehingga terpapar estrogen dalam jangka waktu lama akan memiliki risiko yang besar terhadap terjadinya kanker payudara. ${ }^{10}$ Sebenarnya hormon estrogen mempunyai peran penting untuk perkembangan seksual dan fungsi organ kewanitaan, selain itu estrogen juga berperan dalam pemeliharaan jantung dan tulang yang sehat. Namun pajanan estrogen dalam waktu lama berpengaruh terhadap terjadinya kanker payudara karena hormon ini dapat memicu pertumbuhan tumor. ${ }^{11,12}$

Penggunaan KB hormonal juga dapat memicu timbulnya kanker payudara dibandingkan dengan penggunaan KB non hormonal. Alat kontrasepsi hormonal mengandung hormone-hormon respoduksi perempuan dan di Indonesia penggunaan alat kontrasepsi hormonal baik pil (31\%), suntik $(38,5)$ maupun susuk $(12,3 \%)$ sudah umum dilakukan. ${ }^{12}$ Berdasarkan hasil penelitian Indrati, ${ }^{9}$ wanita yang menggunakan kontrasepsi oral > 10 tahun memberikan risiko sebesar 3-10 kali dibandingkan dengan wanita yang tidak menggunakan kontrasepsi oral. Penelitian Harianto et $a 1^{11}$ menunjukkan bahwa pengguna pil kontrasepsi kombinasi memiliki risiko 1,864 kali lebih tinggi untuk terkena kanker payudara dibandingkan dengan bukan pengguna pil kontrasepsi kombinasi. Hingga saat ini masih menjadi perdebatan mengenai pengaruh kontrasepsi oral terhadap kejadian kanker payudara karena hal tersebut juga dipengaruhi oleh kadar estrogen yang terdapat di dalam pil kontrasepsi, lama pemakaian, dan usia saat menggunakan kontrasepsi tersebut. ${ }^{11,12}$

Hasil uji Spearman Rho didapatkan hasil nilai significancy 0,938 ( $p>0,05)$ yang menunjukkan bahwa korelasi antara religiusitas dengan tindakan skrining kanker payudara pada wanita di wilayah kerja Puskesmas Pandak I, Kabupaten Bantul, Yogyakarta tidak bermakna dengan nilai korelasi Spearman sebesar 0.004 yang menunjukkan bahwa arah korelasi positif dengan kekuatan korelasi yang sangat lemah.

Hasil penelitian ini sejalan dengan penelitian yang dilakukan oleh Padela et $\mathrm{al}^{14}$ yang menyatakan bahwa religiusitas tidak berhubungan dengan perilaku pernah melakukan mammografi ataupun melakukan 
mammografi dalam 2 tahun terakhir. Hasil penelitian yang berbeda didapatkan dari penelitian yang dilakukan oleh Leyva et al, ${ }^{15}$ yang melaporkan bahwa religiusitas berhubungan dengan semakin besarnya penggunaan fasilitas untuk skrining kanker terutama kanker payudara, servik, dan kolorektal.

Nilai religiusitas dapat memengaruhi perilaku pencegahan penyakit melalui cara yang faktor sosioekonomik maupun akulturatif tidak dapat lakukan. Sebagai contoh, pada penelitian yang diakukan oleh Padela $^{16}$ mendapatkan hasil pada individu yang beragama Islam, maka perilaku kesehatan yang dilakukan juga akan dipengaruhi oleh nilai-nilai ke-Islaman seperti percaya bahwa kesehatan hanya berasal dari Tuhan, memiliki panduan khusus dalam memilih terapi sesuai tuntunan agama dan tetap menjaga norma kesopanan.

Religiusitas juga dapat mempengaruhi keputusan seseorang mengenai hal hal yang berhubungan dengan kesehatannya $^{(5)}$. Beberapa wanita yang memiliki keyakinan religi atau religiusitas yang tinggi akan menempatkan keyakinan tersebut sebagai acuan dalam segala tindakan yang berhubungan dengan sehat maupun sakit. ${ }^{3}$ Sebagai contoh, Mitchell et $\mathrm{al}^{17}$ menemukan wanita African American lebih percaya bahwa religious intervention berupa berdoa memiliki kekuatan yang lebih tinggi dibandingkan dengan pengobatan medis, sehingga banyak dari wanita tersebut terlambat melakukan palpasi payudara sebagai upaya untuk deteksi dini kanker payudara dan akhirnya terlambat mencari pertolongan untuk kanker payudara yang dialaminya.

Religiusitas juga memainkan peran penting dalam kehidupan seseorang dengan pengaruhnya terhadap kognitif, afektif, motivasi dan juga perilaku orang tersebut, termasuk didalamnya mengatur norma kesopanan seseorang. ${ }^{18}$ Berdasarkan penelitian, pada wanita Asian Indian, norma kesopanan merupakan suatu halangan untuk melakukan skrining kanker payudara karena norma tersebut mempengaruhi kemauan wanita untuk menyentuh bagian pribadinya, memperbolehkan dokter melakukan pemeriksaan payudara, dan membicarakan mengenai skrining kanker payudara pada keluarga atau petugas kesehatan. ${ }^{19}$

Hasil penelitian pada wanita di Asia selatan menunjukkan bahwa ada pilihan dengan dasar yang kurang jelas dari para wanita tersebut untuk mau menjalani skrining kanker payudara antara lain beberapa wanita menyatakan bahwa mereka hanya mau diperiksa oleh dokter dengan jenis kelamin wanita, ragu apabila diperiksa dokter yang berasal dari latar belakang budaya yang sama dan beberapa sangat concern terhadap kompetensi dan sensitivitas dari dokter tersebut. $^{3}$

Jawaban terbanyak dari penelitian ini mengenai alasan tidak melakukan skrining kanker payudara adalah percaya bahwa 
kesehatan sudah ditentukan oleh Tuhan (36.5\%). Hal serupa pernah dikemukakan oleh Gullate et $\mathrm{al}^{5}$ yang menyatakan bahwa keterlambatan mencari pertolongan pelayanan kesehatan pada wanita African America disebabkan karena para wanita African American ini percaya bahwa segala sesuatunya sudah diatur oleh tuhan dan lebih memilih untuk menjalani religious intervention daripada intervensi medis. Hasil jawaban pada tabel 4 mendukung hasil analisis bivariat dari penelitian ini bahwa korelasi antara religiusitas dengan tindakan skrining kanker payudara pada wanita di di wilayah kerja Puskesmas Pandak I, Kabupaten Bantul, Yogyakarta tidak bermakna dengan korelasi yang sangat lemah karena responden lebih memilih untuk memasrahkan kesehatannya pada Tuhan yang dianggap lebih berkuasa daripada tindakan medis mana pun.

\section{KESIMPULAN}

Tidak ada hubungan antara religiusitas dengan skrining kanker payudara pada wanita di wilayah kerja Puskesmas Pandak I, Kabupaten Bantul, Yogyakarta (Pv: 0,938,Sig:0,05) dengan arah hubungan positif dan kekuatan sangat lemah $(0,004)$. Gambaran karakteristik responden berdasarkan demografi adalah mayoritas berusia $20-50$ tahun (81.1\%), berpendidikan SMA (47.6\%), bekerja pada sektor swasta (48\%), menikah (89.7\%), dan beragama Islam (73.3\%).
Gambaran faktor risiko kanker payudara pada responden adalah mayoritas responden berada pada resiko rata rata kecuali untuk riwayat menarche dini/di bawah 12 tahun (71\%) dan mengikuti KB hormonal (56.9\%) yang termasuk dalam kategori resiko tinggi. Gambaran tingkat resligiusitas responden mayoritas berada pada kategori sedang (77.3\%). Gambaran tindakan skrining kanker payudara pada responden mayoritas berada pada kategori kurang (59.4\%).

\section{KEPUSTAKAAN}

1. Kementrian Kesehatan Republik Indonesia.Situasi penyakit kanker. Buletin Jendela Data dan Informasi Kesehatan. 2015. Tersedia dalam http://www.depkes.go.id/resources/downl oad/pusdatin/buletin/buletin-kanker.pdf. diakses tanggal 10 April 2016.

2. Khalili,A.F.,Shahnazi,M. Breast cancer screening (breast self examination, clinical breast exam, and mammography) in women referred to health centers in Tabriz, Iran. Indian Journal Of Medical Sciences, April 2010, Vol 64, No.4.

3. Boxwala,F.I.,Bridgemohan,A.,Griffith,D.M. ,Soliman,A.S. Factors associated with breast cancer screening in asian indian women in metro- detroit. $J$ Immigrant Minority Health, 2009,12:534-543.

4. Gullate,M.M. The influence of spirituality and religiosity on breast cancer screening delay in african american women: application of the theory of reasoned action dan planned behavior (tra/tpb). The ABNF Journal,Spring.2006.

5. Gullate,M.M.,Brawley,O.,Kinney,A.,Powe, B.,Mooney,K. Religiosity, spirituality, and cancer fatalism beliefs on delay in breast cancer diagnosis in african american women. J Religi Health, 2009,49:62-72.

6. Kudel,I.,Cotton,S.,Szaflarski,M.,Holmes, W.,et al. Spirituality and religiosity in patients with HIV: a test and expansion of a model. Ann behav med. 2011,41:92103. DOI:10.1007/s12160-010-9229-x. 
7. Ironson,G.,Stuetzle,R.,Fletcher,M.A. An increase in religiousness/spirituality occurs after HIV diagnosis and predicts slower disease progression over 4 years in people with HIV. J Gen Intern Med 2006;21 Suppl 5:S62-S68.

8. American Cancer Society. Breast Cancer Risk and Prevention. 2016. Tersedia dalam

https://www.cancer.org/content/dam/CRC /PDF/Public/8578.00.pdfdiakses tanggal 10 Oktober 2017.

9. Indrati R. Faktor-faktor risiko yang berpengaruh terhadap kejadian kanker payudara wanita (studi kasus di Rumah Sakit Dokter Kariadi Semarang). Thesis. Semarang: Program Pascasarjana, Universitas Diponegoro. 2005. Tersedia dalam

http://eprints.undip.ac.id/14998/1/2005E4 D002071.pdf. diakses tanggal 10 Oktober 2017.

10. Sirait AM, Oemiati $R$ dan Indrawati $L$. Hubungan kontarsepsi pil dengan tumor/kanker payudara di Indonesia. Majalah Kedokteran Indonesia. 2009;59(8):348-356.

11. Harianto, Mutiara $R$ dan Surachmat $H$. Risiko penggunaan pil kontrasepsi kombinasi terhadap kejadian kanker payudara pada reseptor KB di perjan $\mathrm{RS}$ DR.Cipto Mangunkusumo. Majalah IImu Kefarmasian. 2005;2(1):84-99.

12. Sihombing,M Dan Sapardin,A.N. Faktor Risiko Tumor Payudara Pada Perempuan Umur 25-65 Tahun Di Lima Kelurahan Kecamatan Bogor Tengah. 2014. tersedia dalam

http://ejournal.litbang.depkes.go.id/index. php/kespro/article/view/3895/3740

diakses tanggal 10 Oktober 2017

13. Nurdiana E, Widyantoro N. Informasi Kesehatan Reproduksi Perempuan. Yayasan Lembaga Konsumen Indonesia. 2002. Yogyakarta: Galang Printika.

14. Padela,Al.et al. Religious Beliefs and mammography intention: finding from a qualitative study of a diverse group of American muslim women. Paper. Psychooncology 2016: 1-8. John Wiley \& Sons.

15. Leyva et al. Is religiosity Associated with Cancer Screening? Result from a national
Survey. Journal Religi Health 2015 (54): 998-1013.

16. Padela,Al.et al. Association Between Religion - Related factors and Cervical Cancer Screening Among Muslims in Greater Chicago. Journal of lower genital tract disease,November 2014,00(00):1-9.

17. Mitchell, J., Lannin, D. R., Matthews, H. F., \& Swanson, M. S. Religious beliefs and breast cancer screening. Journal of Women's Health, 2002, 11: 907-915. DOI:10.1089/154099902762203740.

18. Jang,J.E.,Kim,S.W.,Kim,S.Y.,Kim,J.M.,et al. Religiosity, depresion, and quality of life in Korean patients with breast cancer: a 1 year prospective longitudinal study. Psycho oncology 2013, 22:922-929. DOI: 10.1002/pon.3083

19. Ahmad,F., Cameron,J.I., Stewart, D.E. A tailored intervention to promote breast cancer screening among south asian women. Soc Sci Med. 2005;60:575-86. 